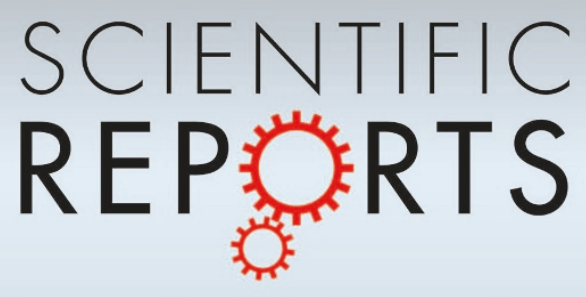

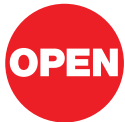

SUBJECT AREAS:

ELECTROCATALYSIS

STRUCTURAL PROPERTIES

FUEL CELLS

SYNTHESIS OF GRAPHENE

Received

12 March 2013

Accepted

17 April 2013

Published

3 May 2013

Correspondence and requests for materials should be addressed to S.J.L. (chsjliao@scut. edu.cn)

\section{High Performance Fe- and N- Doped Carbon Catalyst with Graphene Structure for Oxygen Reduction}

\author{
Hongliang Peng 1,2,3, Zaiyong Mo',2, Shijun Liao ${ }^{1,2}$, Huagen Liang ${ }^{1,2}$, Lijun Yang ${ }^{1,2}$, Fan Luo ${ }^{1,2}$, \\ Huiyu Song ${ }^{1,2}$, Yiliang Zhong ${ }^{1,2}$ \& Bingqing Zhang ${ }^{1,2}$
}

${ }^{1}$ School of Chemistry and Chemical Engineering, South China University of Technology, Guangzhou, 510641, China, ${ }^{2}$ Key Lab for Fuel Cell Technology of Guangdong Province \& Key Lab of New Energy Technology of Guangdong Universities, ${ }^{3}$ School of Chemistry and Chemical Engineering, Hunan University of Science and Technology, Xiangtan, 411201 , China.

Proton exchange membrane fuel cells are promising candidates for a clean and efficient energy conversion in the future, the development of carbon based inexpensive non-precious metal ORR catalyst has becoming one of the most attractive topics in fuel cell field. Herein we report a Fe- and $\mathrm{N}$ - doped carbon catalyst Fe-PANI/C-Mela with graphene structure and the surface area up to $702 \mathrm{~m}^{2} \mathrm{~g}^{-1}$. In $0.1 \mathrm{M} \mathrm{HClO}_{4}$ electrolyte, the ORR onset potential for the catalyst is high up to $0.98 \mathrm{~V}$, and the half-wave potential is only $60 \mathrm{mV}$ less than that of the $\mathrm{Pt} / \mathrm{C}$ catalyst (Loadings: $51 \mu \mathrm{g} \mathrm{Pt} \mathrm{cm} \mathrm{cm}^{-2}$ ). The catalyst shows high stability after 10,000 cyclic voltammetry cycles. A membrane electrode assembly made with the catalyst as a cathode is tested in a $\mathrm{H}_{2}$-air single cell, the maximum power density reached $\sim 0.33 \mathrm{~W} \mathrm{~cm}^{2}$ at $0.47 \mathrm{~V}$.

(5)

he oxygen reduction reaction (ORR) on the cathode is an important process in proton exchange membrane fuel cells (PEMFCs). Because the cathodic activation and reduction of oxygen are much more difficult than the anodic activation and oxidation of hydrogen, relatively, large amounts of platinum catalyst must be used on the cathode to accelerate the ORR. Due to platinum's rarity and high cost, Pt catalyst loading is one of the most important factors hindering the commercialization of PEMFCs. Considerable attention has therefore been paid to overcome this problem by developing low-platinum and platinum-free catalysts for PEMFC cathodes ${ }^{1-11}$.

Nitrogen-doped carbon has been recognized as a promising type of cathode catalyst for PEMFCs since Gong et al. ${ }^{12}$ reported the high ORR activity of nitrogen-doped carbon nanotubes in 2009. Currently, investigating doped carbon catalysts for ORR application is becoming one of the hottest topics in the fuel cell field. Many types of nitrogen-doped carbon materials, such as nitrogen-doped carbon nanotubes ${ }^{5,12}$, nitrogen-doped graphene ${ }^{13-15}$, and various metal-N4 complexes ${ }^{16,17}$, have been investigated for their ORR activity. The Dai group ${ }^{12,18}$ found that some metal-free doped carbon nanomaterials even showed ORR activity almost comparable to platinum catalysts' in an alkaline medium. However, there is still a long way to go before such materials have the activity and stability to make them viable replacements for platinum catalysts in practical applications, especially in acidic media.

To improve the performance of doped carbon catalysts, some researchers have investigated the addition of metal species, and significantly enhanced performance has been achieved. Recently, Wu et al. ${ }^{3}$ reported a highperformance doped carbon catalyst prepared from a polyamine-supported microporous carbon template incorporating iron or cobalt. The catalyst showed high ORR activity (the ORR onset potential was ca. $0.93 \mathrm{~V}$ vs. RHE) and excellent stability for $700 \mathrm{~h}$ of long-term testing.

The Dodelet group reported Fe/Phen/BP catalyst ${ }^{19}$ and Fe/Phen/Z8 catalyst ${ }^{17}$, prepared by milling a mixture of carbon black BP (Black Pearl, Cabot) or the metal-organic framework material Z8, phenanthroline, and ferrous acetate, followed by pyrolyzing the mixture twice, first in argon, then in ammonia. The catalysts showed excellent performance at the cathode of PEMFCs, the best being the Fe/Phen/Z8 catalyst, with a volumetric activity of $230 \mathrm{~A} \mathrm{~cm}^{-3}$ at $0.8 \mathrm{~V}$ (iR-free). They believed that the high activity may have resulted from the high density of active sites on the catalyst, possibly caused by the high micropore surface area of the support and the fact that many of the iron cations were coordinated by pyridinic nitrogen functionalities in the interstices of the graphitic sheets within the micropores. Choi et al. ${ }^{9}$ prepared two types of FeCo/EDA-carbon catalysts, using Ketjen Black 600 (ca. $\left.1416 \mathrm{~m}^{2} \mathrm{~g}^{-1}\right)$ and Ketjen Black $300\left(\mathrm{ca} .823 \mathrm{~m}^{2} \mathrm{~g}^{-1}\right)$ as the respective carbon supports. They found that 


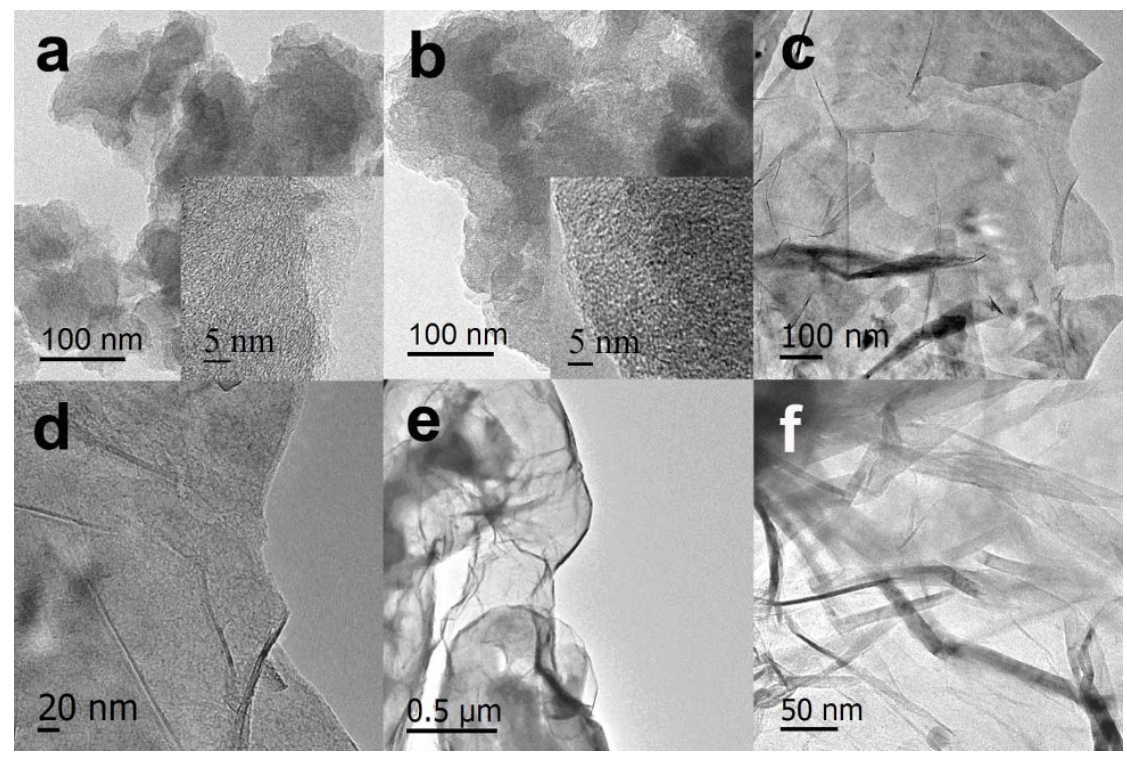

Figure 1 TEM images of samples C-PANI (a), PANI/C-Mela (b), and Fe-PANI/C-Mela (c, d, e, f), prepared at a pyrolysis temperature of $900{ }^{\circ} \mathrm{C}$ in an Ar atmosphere.

the higher surface area may result in high active site density, and thus in high activity. This suggestion was also supported by the work of Liang et al. ${ }^{20}$ and Wang et al. ${ }^{13}$.

In the present study, a high-performance doped carbon electrocatalyst was prepared by pyrolyzing a hybrid precursor in an $\mathrm{Ar}$ atmosphere. The precursor was made by impregnating melamine with a solution of $\mathrm{FeCl}_{3}$ and aniline, followed by polymerizing the aniline and covering the melamine with it. Interestingly, the prepared catalyst possesses a graphene structure and demonstrates a high surface area (up to ca. $702 \mathrm{~m}^{2} \mathrm{~g}^{-1}$ ), as well as high pyridinic-N and graphitic-N content, high activity in an acidic medium, and high stability.

\section{Results}

Structure characterizations. Figure 1 shows TEM images of CPANI, PANI/C-Mela, and Fe-PANI/C-Mela. It is clear that the CPANI (Figure 1a) prepared from pure polyaniline had a good graphite-like layer structure with BET surface area ca. $392 \mathrm{~m}^{2} \mathrm{~g}^{-1}$. However, once melamine was added to the precursor, the resulting PANI/C-Mela (Figure 1b) showed a slightly altered mixed structure, has some different from C-PANI; its ordering seems lower than that of C-PANI and the BET surface area of PANI/C-Mela is ca. $521 \mathrm{~m}^{2}$ $\mathrm{g}^{-1}$, implying that mixing melamine with the precursor affected the structure of the final samples. It is very important that further doping of the PANI/C-Mela system with Fe resulted in the formation of thin, transparent graphene-like nanosheets, as shown in Figure 1 (c, d, e, and $\mathrm{f}$ ). The surface area of the catalyst reached $702 \mathrm{~m}^{2} \mathrm{~g}^{-1}$, which is higher than that of the graphene-based carbon nitride catalyst reported by Yang et $\mathrm{al}^{21}$. $\left(542 \mathrm{~m}^{2} \mathrm{~g}^{-1}\right)$, and almost the same as that of graphene nanosheets prepared under ultralow exfoliation temperature $\left(750 \mathrm{~m}^{2} \mathrm{~g}^{-1}\right)^{22}$. Actually, this result of high surface area further confirms the catalyst's graphene structure. It seems that the Fe acted as the catalyst for the formation of graphene. It is interesting that we hardly observe the particles of iron or iron compound in TEM images of the Fe-PANI/C-Mela sample, although the results of XRD and XPS revealed its existence, we believe most iron has been removed in the process of acid leaching.

Figure 2a compares the Raman spectra of C-PANI, PANI/C-Mela, and Fe-PANI/C-Mela. The ratios of the $\mathrm{D}$ band to $\mathrm{G}$ band integrated intensity $\left(\mathrm{I}_{\mathrm{D}} / \mathrm{I}_{\mathrm{G}}\right)$ for the three samples are 2.35, 2.39, and 1.22, respectively. Figure $2 \mathrm{~b}$ shows the FTIR spectra of C-PANI, PANI/ $\mathrm{C}-\mathrm{Mela}$, and Fe-PANI/C-Mela. According to the literature, the bands at $\sim 1243.2, \sim 1225.2$, and $\sim 1215.0 \mathrm{~cm}^{-1}$, as well as the bands at $\sim 1589.3, \sim 1569.9$, and $\sim 1575.7 \mathrm{~cm}^{-1}$, can be assigned to the coordination-bonded, pyridine-type $\mathrm{C}-\mathrm{N}$ bond ${ }^{23}$ and to the stretching of the C-N bonds ${ }^{24}$. Clearly the bands of PANI/C-Mela and Fe-PANI/ $\mathrm{C}$-Mela are much stronger than those of C-PANI, implying that the catalysts containing melamine include more certain $\mathrm{C}-\mathrm{N}$ bonds.
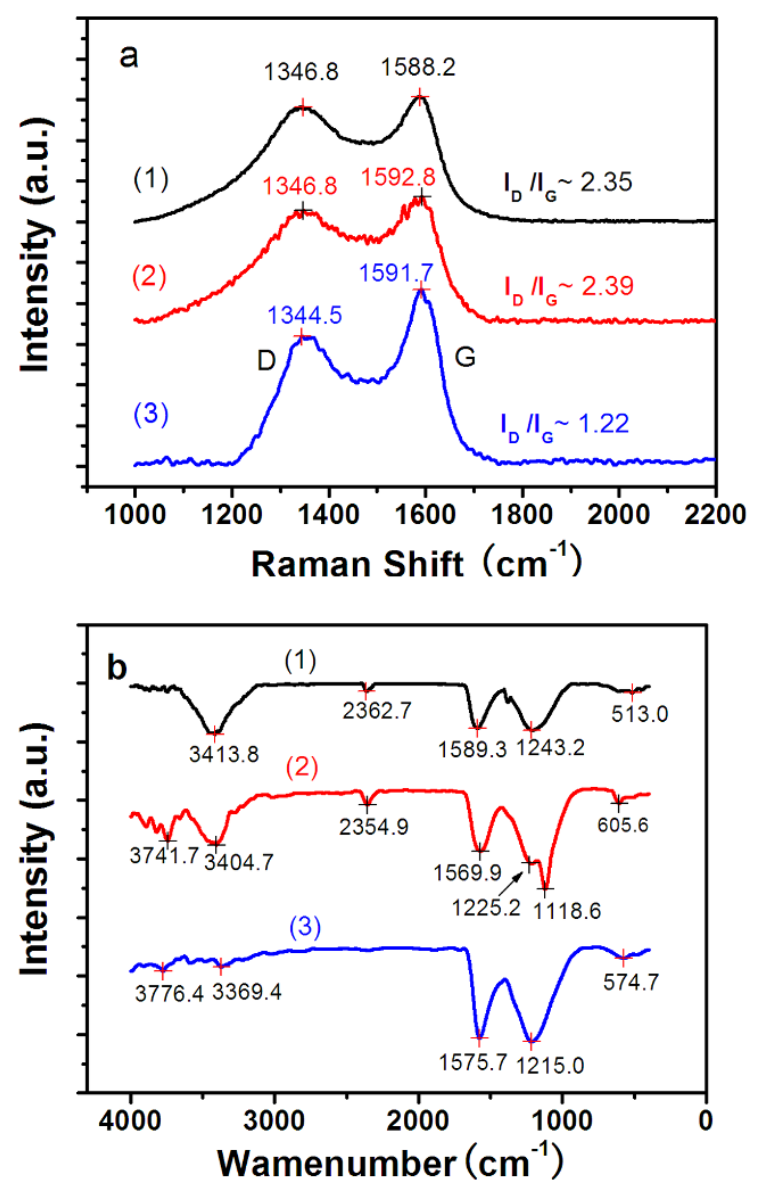

Figure $2 \mid$ Raman (a) and FTIR (b) spectra of doped catalysts. (1) C-PANI, (2) PANI/C-Mela, (3) Fe-PANI/C-Mela. 
As shown in Figure 3, the XPS results reveal the chemical state of doped $\mathrm{N}$ and Fe elements in Fe-PANI/C-Mela catalyst. The N1S spectrum (Figure 3a) can be deconvoluted into five peaks at 398.2, $399.1,399.6,400.8$, and $401.9 \mathrm{eV}$, which can be assigned to pyridinic $\mathrm{N}^{25}, \mathrm{~N}-\mathrm{Fe}$ compounds ${ }^{16}$, benzenoid amine $(-\mathrm{NH}-)^{26}$, graphitic $\mathrm{N}^{17,19,25,27}$, and oxidized nitrogen compounds ${ }^{28}$, with compositions of $24.2,10.7,5.9,41.9$, and 17.3 at $\%$, respectively. Our catalyst clearly has high graphitic $\mathrm{N}$ content (41.9 at $\%$ in total doped nitrogen) and high pyridinic $\mathrm{N}$ content (24.2 at\%).

Figure $3 \mathrm{~b}$ shows the Fe $2 \mathrm{p}$ spectrum, it can also be deconvoluted into five peaks at 710.7, 713.6, 718.7, 722.9, and 725.2 eV. The photoelectron peaks at $725.2 \mathrm{eV}$ is correspond to the binding energies of $2 \mathrm{p}$ $1 / 2$ of $\mathrm{Fe}(\mathrm{III})$ and $\mathrm{Fe}(\mathrm{II})$ ion $^{29}$, the peaks at $722.9 \mathrm{eV}$ can be assigned to the binding energies of $2 \mathrm{p} 1 / 2$ of $\mathrm{Fe}(\mathrm{II})$ ion $^{30}$. The peak at $713.6 \mathrm{eV}$ and $710.7 \mathrm{eV}$ can be assigned to the $2 \mathrm{p} 3 / 2$ of Fe(II) ion ${ }^{31}$ and $\mathrm{Fe}(\mathrm{III})$ ion $^{32}$, respectively. The peak at $718.7 \mathrm{eV}$ is a satellite peak for the above four peaks. Indicating the co-existing of $\mathrm{Fe}(\mathrm{II})$ and $\mathrm{Fe}(\mathrm{III})$ in the catalyst.

The XRD patterns shown in Figure 4 display the structures of the catalyst prepared at various conditions. Figure $4 \mathrm{a}$ shows the XRD patterns of Fe-PANI/C-Mela catalysts pyrolyzed at various temperatures. With the increase of pyrolysis temperature, the peaks of carbon at $2 \theta$ of 21.7 and 26.3 varied obviously (short dash in Figure $4 a$ ). The intensity of the peaks at $2 \theta$ of 26.3 gets strong with the increase of pyrolysis temperatures, indicating the changing of the structure of the carbon in catalyst. It should be point out that when the pyrolysis temperature is getting higher than $800^{\circ} \mathrm{C}$, the six characteristic diffraction peaks ((220), (311), (400), (422), (511), and (440)) of $\mathrm{Fe}_{3} \mathrm{O}_{4}$
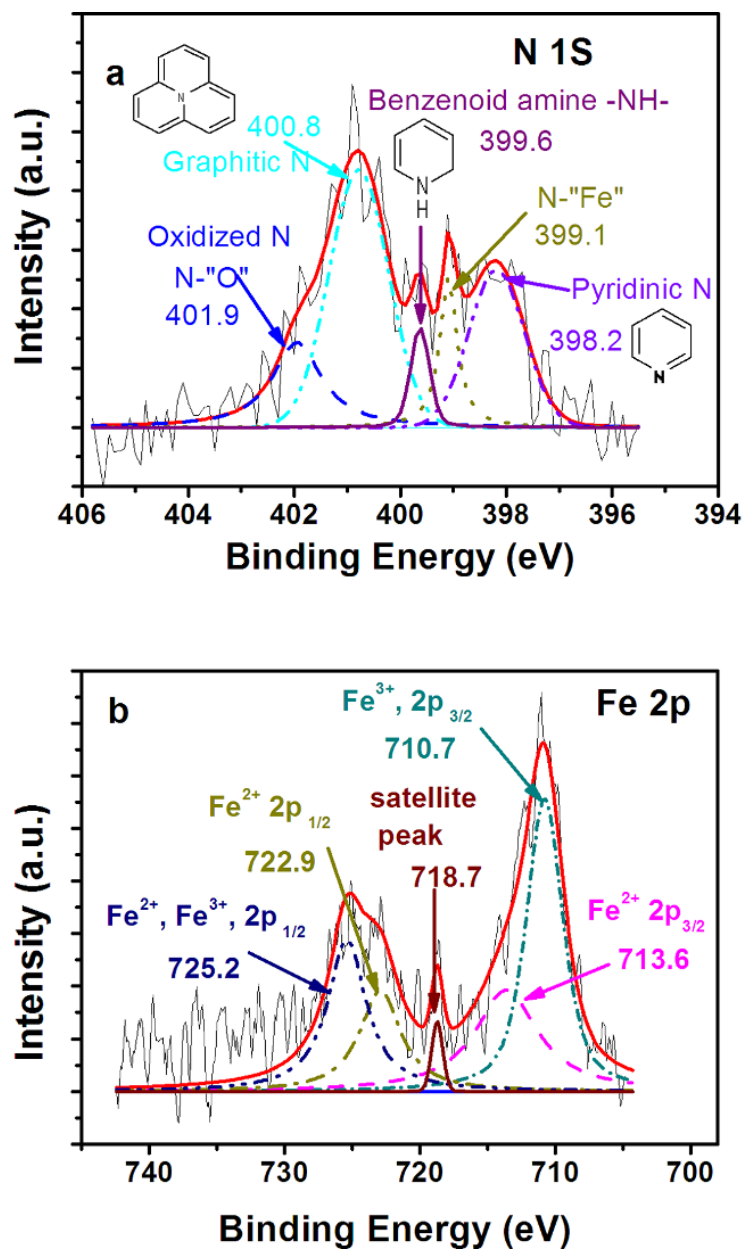

Figure $3 \mid$ The high resolution XPS spectra of N1s (a) and Fe 2p (b) of FePANI/C-Mela catalyst.
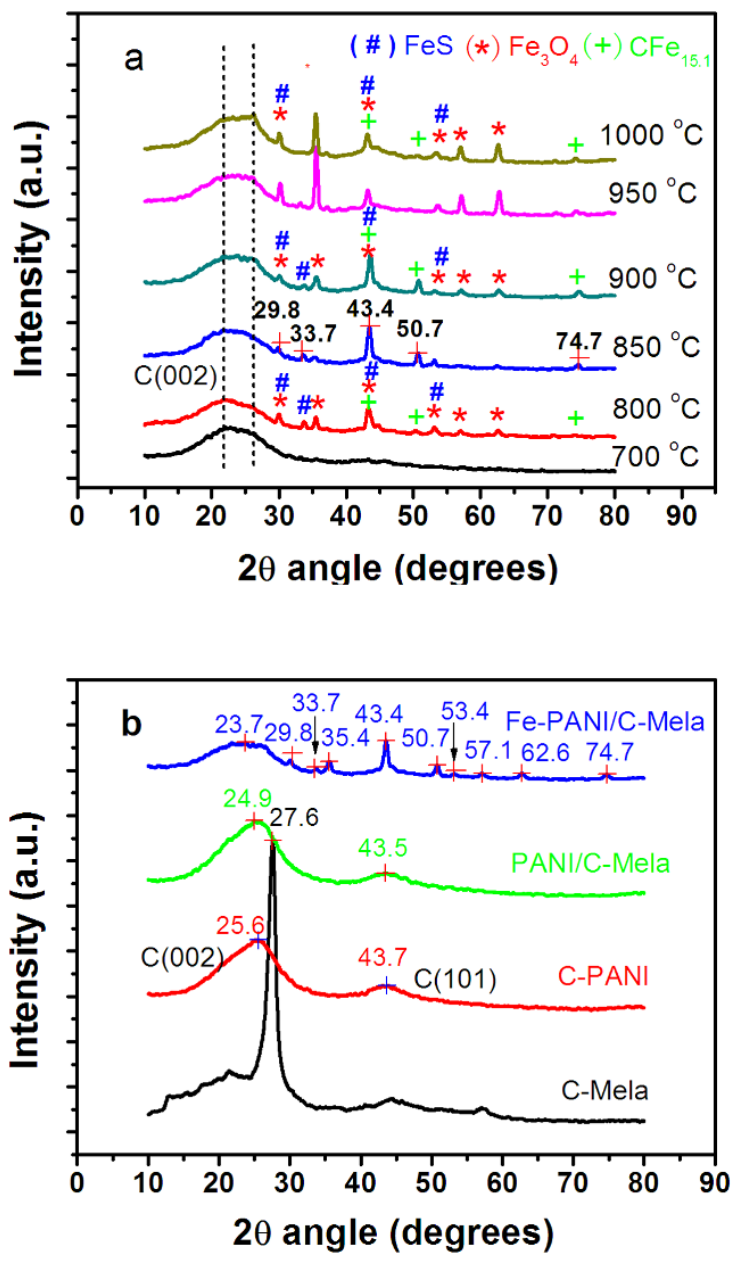

Figure $4 \mid$ XRD patterns of (a) Fe-PANI/C-Mela catalyst prepared at various pyrolysis temperatures, (b) samples Fe-PANI/C-Mela, $\mathrm{PANI} / \mathrm{C}-\mathrm{Mela}, \mathrm{C}-\mathrm{PANI}$ and C-Mela prepared at pyrolysis temperature of $900^{\circ} \mathrm{C}$.

are emerged, and get strong with the increase of pyrolysis temperatures, implying the formation of $\mathrm{Fe}_{3} \mathrm{O}_{4}$. However, once the pyrolysis temperature is increased to $850^{\circ} \mathrm{C}$, five peaks at $29.8,33.7,43.4,50.7$ and $74.7^{\circ}$ of $2 \theta$ become clear, the peaks at $29.8,33.7$, and $43.4^{\circ}$ can be assigned to the (100), (101) and (102) planes of FeS respectively; and the peaks at $43.4,50.7$ and $74.7^{\circ}$ can be assigned to the (111), (200) and (220) planes of austenite $\left(\mathrm{CFe}_{15.1}\right)$, indicating the co-existence of $\mathrm{Fe}_{3} \mathrm{O}_{4}, \mathrm{FeS}$ and austenite in the sample prepared over $850^{\circ} \mathrm{C}$. Actually, the strongest peak at $43.4^{\circ}$ of $2 \theta$, appeared in the patterns of samples prepared by pyrolyzing at 800,850 , and $900^{\circ} \mathrm{C}$, is a piledup peak of $\mathrm{FeS}$ (102), $\mathrm{Fe}_{3} \mathrm{O}_{4}$ (400) and $\mathrm{CFe}_{15.1}$ (111). It is interesting that $\mathrm{CFe}_{15.1}(200)$ peak at $2 \theta$ of $50.7^{\circ}$ gets strongest at $900^{\circ} \mathrm{C}$, and is disappeared at $950^{\circ} \mathrm{C}$, whilst the piled-up peak at $43.4^{\circ}$ gets weak significantly, indicating that there are no $\mathrm{CFe}_{15.1}$ existed in the samples prepared over $950^{\circ} \mathrm{C}$. As we will discuss later, the sample prepared at $900^{\circ} \mathrm{C}$ shows best activity, it means that maybe $\mathrm{FeS}$ and austenite $\mathrm{CFe}_{15.1}$, but not $\mathrm{Fe}_{3} \mathrm{O}_{4}$, promotes the performance of the Fe-PANI/C-Mela catalyst.

Figure $4 \mathrm{~b}$ compared the XRD patterns of several samples pyrolyzed from various precursors, it is interesting that the sample CMela shows a strong and narrow diffraction peak at $2 \theta$ of $27.6^{\circ}$, which may be assigned to the carbon materials derived from melamine, indicating its high ordered structure. And we should point out that the shift of $\mathrm{C}$ (002) peaks, it shifts from 25.6 of C-PANI to 24.9 of PANI/C-Mela, and 23.7 of Fe-PANI/C-Mela, indicates that the increase of inter-layer distances with the doping of melamine, which 
brings more nitrogen atoms in the catalyst, and the further doping of Fe.

Activity and stability towards ORR. From Figure 5 a we can see that the C-Mela prepared by pyrolyzation from pure melamine shows no ORR activity and the C-PANI shows only poor activity toward the ORR. However, the addition of melamine and iron to C-PANI is greatly enhances the ORR activity. The Fe-PANI/C-Mela catalyst exhibits unexpectedly high ORR activity, with an onset potential up to $0.98 \mathrm{~V}$ (vs. RHE), while its half-wave potential is only $60 \mathrm{mV}$ less than that of JM $40 \mathrm{wt} . \% \mathrm{Pt} / \mathrm{C}\left(51 \mu \mathrm{g} \mathrm{Pt} \mathrm{cm}{ }^{-2}\right)$, and its limited diffusion current is comparable to that of JM Pt/C. To our knowledge, the catalyst is among the best ones of reported doped carbon catalysts for ORR in an acidic medium so far. We found that the ratio of melamine to aniline in the precursors affects the catalytic activity, the optimal ratio being $1: 2$ by weight and the optimal Fe content being ca. 5 wt.\% (see Figure S1, S2 in additional information).

Figure $5 \mathrm{~b}$ shows the effect of pyrolysis temperature on the ORR activity of Fe-PANI/C-Mela catalyst. It is clearly that the optimal temperature is $900^{\circ} \mathrm{C}$ for our catalyst system, as higher or lower will yield inferior activity.

It is important that the Fe-PANI/C-Mela catalyst shows high stability. As shown in Figure 5c, its performance loss calculated from linear regression is in the range of 1.5 to $27.4 \%$ after 10,000 cycles of rotating disk electrode (RDE) testing, at $0.75 \mathrm{~V}$ it is ca. $27.4 \%$, and at $0.85 \mathrm{~V}$ it is ca. $26.5 \%$. Furthermore, it is found that the lower the potential is, the lower the performance loss is. There are only ca. $14 \%$ and $1.5 \%$ performance loss at 0.65 and $0.55 \mathrm{~V}$, respectively.

Single cell performance. Figure 6 shows the single-cell test results when Fe-PANI/C-Mela catalyst was used as the cathode catalyst of the membrane electrode assembly (MEAs). The open cell voltage (OCV) was $\sim 0.96 \mathrm{~V}$ and the maximum power density was $\sim 0.33 \mathrm{~W} \mathrm{~cm}{ }^{-2}$ at $0.47 \mathrm{~V}$ in an $\mathrm{H}_{2}$-air fuel cell, and it is reached the half that of the $\mathrm{Pt} / \mathrm{C}$ single-cell. The current density reached $\sim 400, \sim 640$ and $\sim 800 \mathrm{~mA} \mathrm{~cm} \mathrm{~cm}^{-2}$ at $0.6,0.5$ and $0.4 \mathrm{~V}$, respectively. This is among the best ones of reported doped carbon catalysts for single PEMFC application in an $\mathrm{H}_{2}$-air fuel cell. It should be point out that the stability of Fe-PANI/C-Mela catalyst is still a serious problem, as shown in Figure 6(b), after a long term test of 100 hours, the performance of the single cell is degraded rapidly. The current density decreased to $\sim 50, \sim 120$ and $\sim 230 \mathrm{~mA} \mathrm{~cm}^{-2}$ at 0.6 , 0.5 and $0.4 \mathrm{~V}$, respectively.

Mechanism. The ORR is a multi-electron charge transfer reaction with two main possible paths: one is one step direct pathway, involving four electrons transfer to produce $\mathrm{H}_{2} \mathrm{O}$ directly; another one is two steps indirect pathway, involving two electrons transfer to produce $\mathrm{H}_{2} \mathrm{O}_{2}$ in the first step and then the $\mathrm{H}_{2} \mathrm{O}_{2}$ get another two electrons to transform into $\mathrm{H}_{2} \mathrm{O}$. Generally, the two electron process is less efficient than the four electron process, and the $\mathrm{H}_{2} \mathrm{O}_{2}$ can make materials loss some ORR activity ${ }^{33}$. Therefore, for the oxygen reduction at the cathode of PEM fuel cell, the catalyst, on which the oxygen can be reduced in one step four electron pathway, is the priority in the fuel cell field.

Figure 7a shows the ORR curves of Fe-PANI/C-Mela catalyst at different rotation rates from 800 to $3600 \mathrm{rpm}$. Then four current density values corresponding to the potential of $0.55,0.60,0.65$ and $0.70 \mathrm{~V}$ on every ORR curve were taken. According to the Koutecky-Levich equation as below,

$$
\begin{gathered}
\frac{1}{\mathrm{~J}}=\frac{1}{\mathrm{~J}_{\text {kin }}}+\frac{1}{\mathrm{~J}_{\text {diff }}}=\frac{1}{\mathrm{~J}_{\text {kin }}}+\frac{1}{\mathrm{~B} \cdot \sqrt{\omega}} \\
\mathrm{B}=0.62 \cdot \mathrm{n} \cdot \mathrm{F} \cdot \mathrm{D}^{2 / 3} \cdot \mathrm{v}^{-1 / 6} \cdot \mathrm{C}
\end{gathered}
$$

Plot with $\mathrm{J}^{-1}$ versus $\omega^{-1 / 2}$ at each potential, we can obtain four $\mathrm{J}^{-1}-$ $\omega^{-1 / 2}$ lines derived from these potentials points (Figure $7 \mathrm{~b}$ ). In
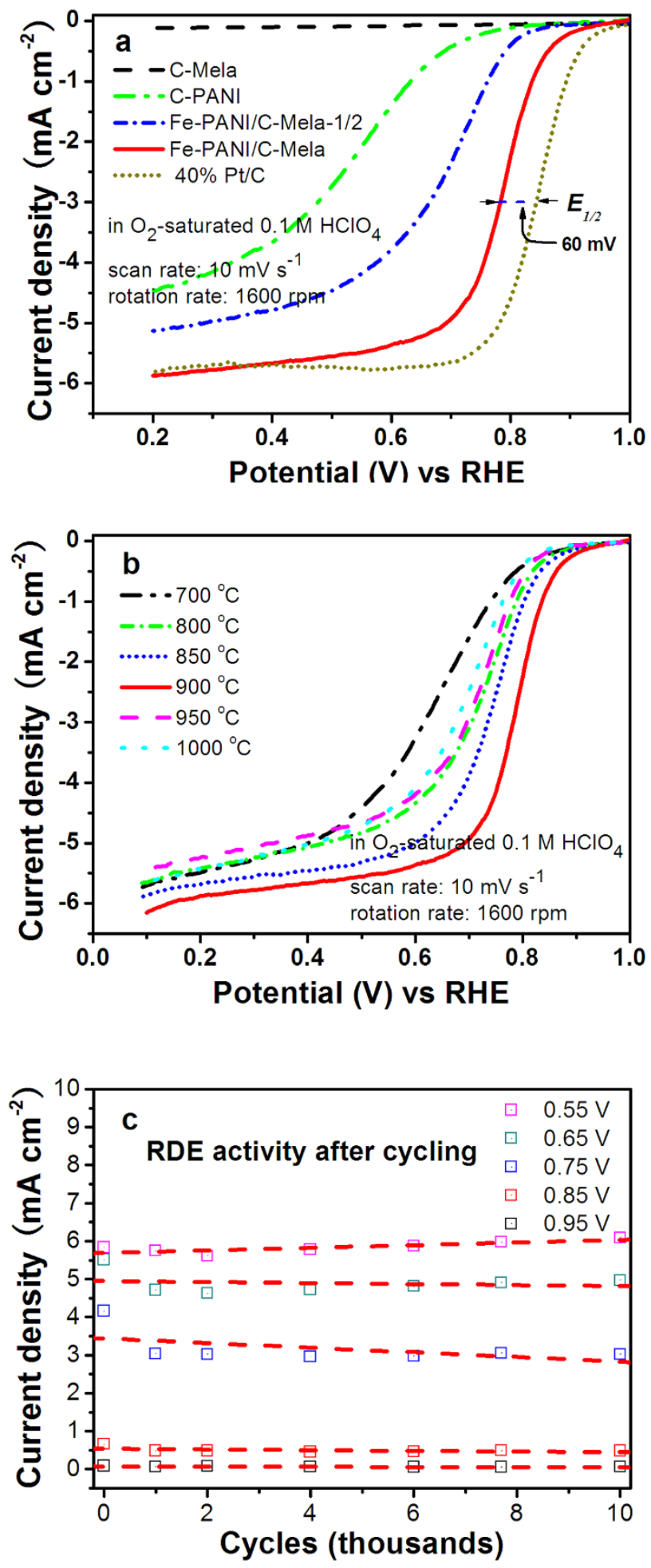

Figure $5 \mid$ ORR polarization plots of (a) C-Mela, C-PANI, Fe-PANI/CMela-1/2, Fe-PANI/C-Mela, and 40 wt.\% JM Hispec $4100 \mathrm{Pt} / \mathrm{C}(51 \mu \mathrm{g} \mathrm{Pt}$ $\mathrm{cm}^{-2}$ ); (b) Series of $\mathrm{Fe}-\mathrm{PANI} / \mathrm{C}-$ Mela catalysts with various pyrolysis temperatures; (c) Fe-PANI/C-Mela catalyst RDE performance at various potentials after potential cycling in air between 0.39 and $1.04 \mathrm{~V}$ in $0.1 \mathrm{M}$ $\mathrm{HClO}_{4}$. (Pt-free catalyst loading: $0.51 \mathrm{mg} \mathrm{cm}{ }^{-2}$, Electrolytes: $\mathrm{O}_{2}$-satruated $0.1 \mathrm{M} \mathrm{HClO}_{4}$, scan rate: $10 \mathrm{mV} \mathrm{s}^{-1}$, rotation rate: $1600 \mathrm{rpm}$ ).

equation (1), the current density $(J)$ consists of a kinetic part $\left(\mathrm{J}_{\text {kin }}\right)$ and a diffusion part $\left(\mathrm{J}_{\text {diff }}\right), \omega$ is the angular velocity of the disk $(\omega=$ $2 \pi \mathrm{N}, \mathrm{N}$ is the linear rotation rate), and $\mathrm{B}$ is a constant, its relation with electron transfer number $\mathrm{n}$. Where $\mathrm{n}$ is the number of electrons 

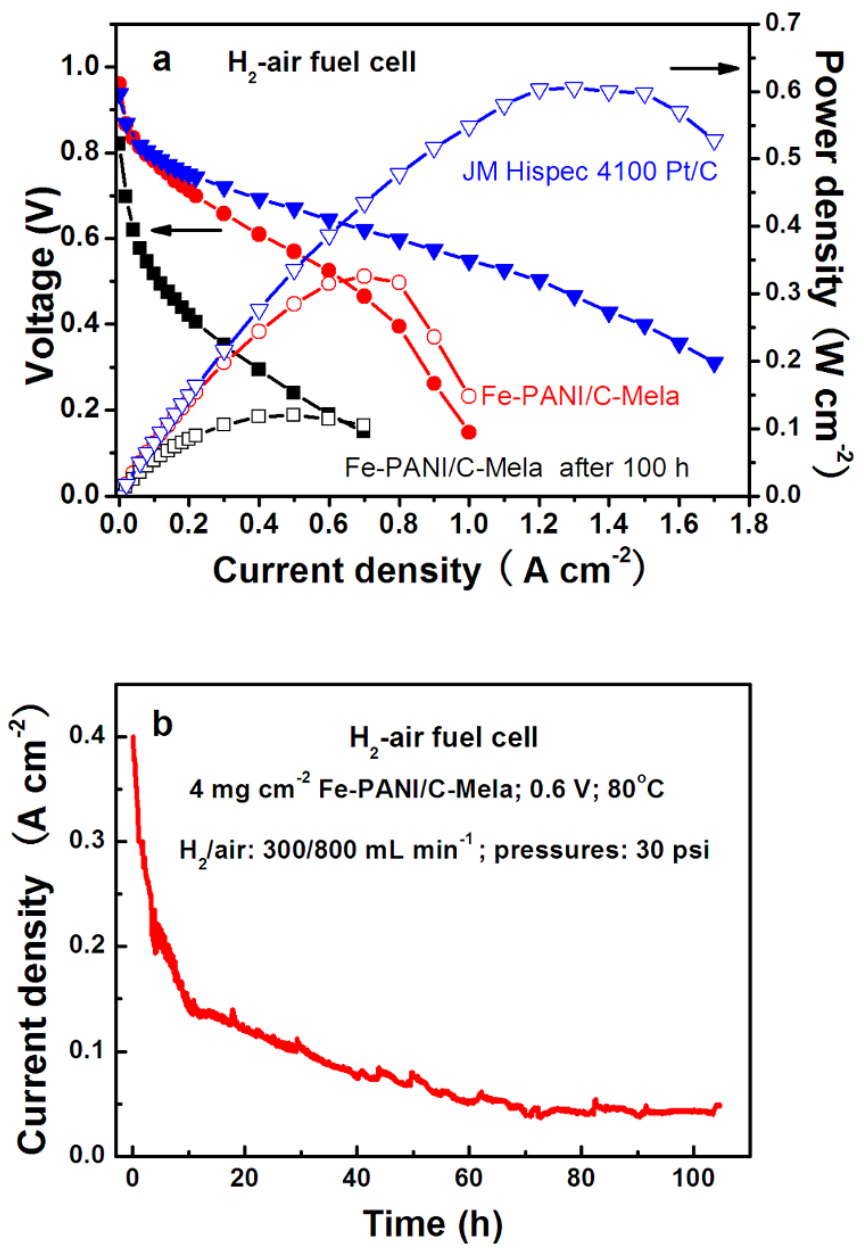

Figure 6 (a) Polarization plots of a single $\mathrm{H}_{2}$-air PEMFC with Fe-PANI/ $\mathrm{C}$-Mela as the cathode before and after long-term stability test (loading: $4 \mathrm{mg} \mathrm{cm}^{-2}$ ), and with JM Pt/C as cathode (Pt loading: $0.2 \mathrm{mg} \mathrm{cm}^{-2}$ ).

(b) The relationship of current density of single cell with Fe-PANI/C-Mela cathode and running time, at a constant fuel cell voltage of $0.60 \mathrm{~V}$.

transferred during the ORR, $\mathrm{F}$ is the Faraday constant $(\mathrm{F}=96485 \mathrm{C}$ $\mathrm{mol}^{-1}$ ), D is the diffusion coefficient of $\mathrm{O}_{2}$ in the $0.1 \mathrm{M} \mathrm{HClO}_{4}$ electrolyte $\left(\mathrm{D}=1.93 \times 10^{-5} \mathrm{~cm}^{2} \mathrm{~s}^{-1}\right)$, $\mathrm{C}$ is the bulk concentration of $\mathrm{O}_{2}\left(\mathrm{C}=1.26 \times 10^{-3} \mathrm{~mol} \mathrm{~L}{ }^{-1}\right), v$ is the kinetic viscosity of the electrolyte $\left(v=1.009 \times 10^{-2} \mathrm{~cm}^{2} \mathrm{~s}^{-1}\right)^{34}$.

According to the Koutecky-Levich equation, the slope of the Koutecky-Levich plots is the reverse of $\mathrm{B}$. Thus, combining the equation (2), we calculated the electron transfer number $\mathrm{n}$ from the slope of each line, being $4.08,4.04,4.06$ and 4.37 , at $0.55,0.60,0.65$ and $0.70 \mathrm{~V}$, respectively, the average value is 4.14 , demonstrating that the oxygen reduction on Fe-PANI/C-Mela catalyst followed the fourelectrons transfer pathway.

\section{Discussion}

According to the TEM Figure 1 (c, d, e, and f), the catalyst Fe-PANI/ $\mathrm{C}$-Mela shows a thin, transparent graphene-like nanosheets. In addition, the Raman (Figure 2a) shows that the ratios of the D band to $G$ band integrated intensity $\left(\mathrm{I}_{\mathrm{D}} / \mathrm{I}_{\mathrm{G}}\right)$ from 2.35 and 2.39 of C-PANI and PANI/C-Mela, to 1.22 of Fe-PANI/C-Mela, indicates that the FePANI/C-Mela has fewer $\mathrm{sp}^{3}$ carbon defects and more $\mathrm{sp}^{2}$ carbon, also clearly revealing the catalyst's graphene structure characteristics $^{35}$. Furthermore, the XPS spectra (Figure 3), FTIR spectra (Figure $2 \mathrm{~b}$ ) and XRD spectra (Figure 4) reveal the doped of $\mathrm{N}$ and $\mathrm{Fe}$ in the Fe-PANI/C-Mela catalyst. It means that we prepared a doped graphene structured material with a facile method. Why the
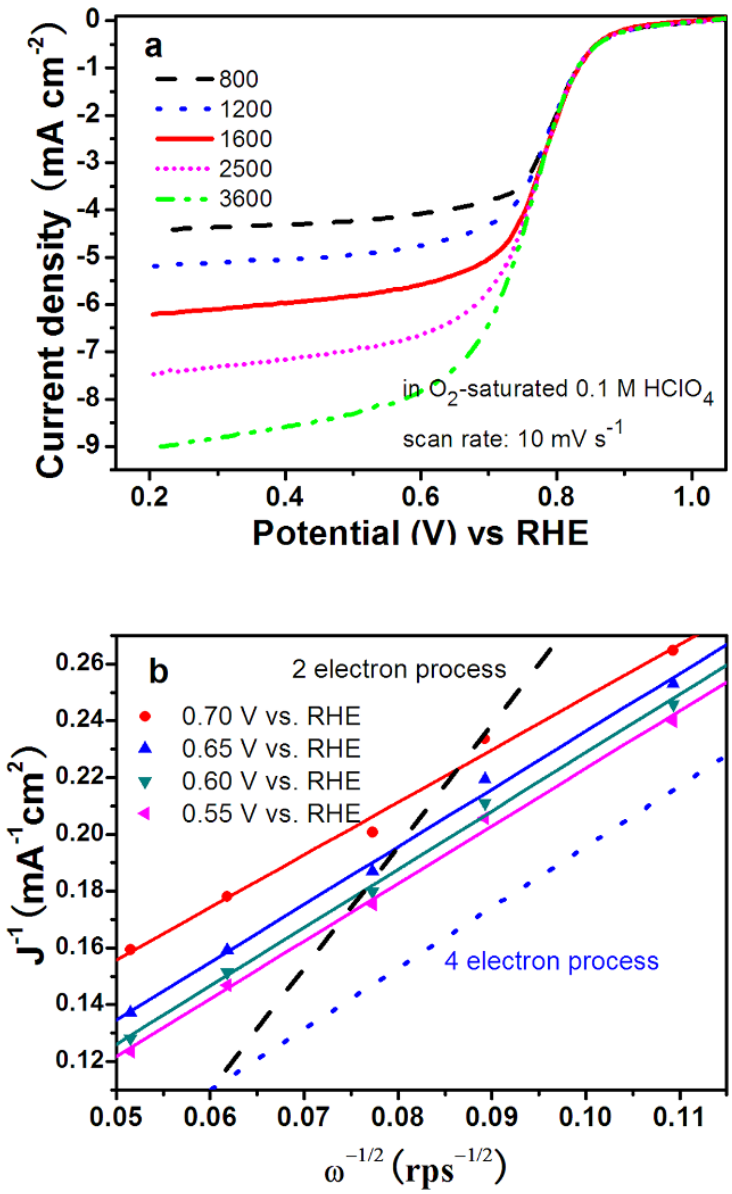

Figure $7 \mid$ (a) ORR polarization plots of Fe-PANI/C-Mela catalyst in $\mathrm{O}_{2}$-saturated $0.1 \mathrm{M} / \mathrm{L} \mathrm{HClO}_{4}$ electrolytes at different rotation rates; (b) Koutecky - Levich plots.

graphene structured material can be derived from melamine and polyaniline precursors with existence of $\mathrm{Fe}$ ? We speculate that it may be related with the planar molecular structure of melamine and linear molecular structure of polyaniline, and the Fe may be played as the catalyst for the formation of graphene structure.

Bezerra et al. ${ }^{36}$ have already presented a good review of the effects of pyrolysis temperature, actually, the optimal pyrolysis temperature depends on the adapted precursors. The temperature may affect both the formation and the density of active sites on the carbon materials.

We found that the pyrolysis temperature affected the structure of doped carbon and the existing status of iron significantly, as shown in Figure 4 and mentioned above, three types of iron, $\mathrm{Fe}_{3} \mathrm{O}_{4}, \mathrm{CFe}_{15.1}$ and $\mathrm{FeS}$ are co-existed in the catalyst, and their ratio varied with the changing of pyrolysis temperature. At the optimal pyrolysis temperature of $900^{\circ} \mathrm{C}$, the ratio of austenite $\mathrm{CFe}_{15.1}$ and $\mathrm{FeS}$ reached highest. implying that it may be the $\mathrm{FeS}$ and $\mathrm{CFe}_{15.1}$ but not the $\mathrm{Fe}_{3} \mathrm{O}_{4}$, play an important role in the formation of active sites, or join in the formation of active sites.

It should point out that XPS spectra just confirm the existence of $\mathrm{Fe}(\mathrm{II})$ and $\mathrm{Fe}$ (III), but not zerovalent iron, it may be caused by two reasons, one is that the zerovalent iron $\left(\mathrm{CFe}_{15.1}\right)$ may be dispersed in the interior of the Fe-PANI/C-Mela nanoparticle, another is that its content may be lower than the detect limitation of XPS. It is found that the sample without of iron addition in the precursor presented very poor performance (See Figure S2). Thus, we can conclude that the iron plays an important role for improving the performance of our Fe-PANI/C-Mela catalyst.

As shown in Figure 5a, the addition of melamine and iron to $\mathrm{C}$ PANI is greatly enhances the ORR activity. The Fe-PANI/C-Mela 
catalyst exhibits unexpectedly high ORR activity which is comparable to that of a state-of-the-art JM Pt/C. This is attributed to the following three reasons. Firstly, the Fe-PANI/C-Mela catalyst has high graphitic $\mathrm{N}$ content (41.9 at $\%$ in total doped nitrogen) and high pyridinic $\mathrm{N}$ content (24.2 at\%) as shown in Figure 3b. It has been acknowledged the graphitic $\mathrm{N}$ plays a crucial role in oxygen reduction $^{37,38}$, and that pyridinic $\mathrm{N}$ and iron cations coordinated with $\mathrm{N}$ can also significantly increase ORR activity ${ }^{19,39,40}$, these may be the main reason that the catalyst presents high ORR activity. Secondly, the $\mathrm{Fe}$ (II) and zerovalent iron promotes the performance of the $\mathrm{Fe}$ PANI/C-Mela catalyst, as we discussed before, the residual iron or iron compound can play an important role in enhancing the catalytic activity $3,16,17,19$. Thirdly, shown in Figure $4 \mathrm{~b}$ that the shift of $\mathrm{C}(002)$ peaks, it shifts from 25.6 of C-PANI to 24.9 of PANI/C-Mela, and 23.7 of Fe-PANI/C-Mela, indicates that the increase of inter-layer distances with the doping of melamine, which brings more nitrogen atoms in the catalyst, and the further doping of Fe. This enlarged distance of graphene layers may benefit to the diffusion of ORRrelated species and enhancement of the catalytic activity.

According to Figure 5c, the Fe-PANI/C-Mela catalyst shows high stability and the performance loss is comparable to that recently reported by Zelenay group ${ }^{3}$, their reported performance loss was 10 to $39 \%$ for their doped carbon catalyst after 10,000 RDE cycles. And our catalyst performance loss is in the range of 1.5 to $27.4 \%$. These results reveal the good stability of our Fe-PANI/C-Mela catalyst towards the reduction of oxygen. We suggest that this good stability may be resulted from the stable graphene structure of the catalyst.

However, in $\mathrm{H}_{2}$-air single fuel cell, the performance and stability of the MEA with Fe-PANI/C-Mela as cathode catalyst are much bad than those of MEA with JM Pt/C catalyst as cathode catalyst. It is clearly that there is still a long way to go to make doped carbon catalyst meet the requirements for practical applications.

In summary, a novel nitrogen- and iron-doped carbon catalyst with a graphene structure, exhibiting high performance for the ORR in an acidic medium, was successfully prepared by pyrolysis with melamine and an iron-containing precursor. The addition of melamine improved the formation of particular C-N bonds, and the further addition of iron gave the catalyst a graphene structure and a high surface area $\left(702 \mathrm{~m}^{2} \mathrm{~g}^{-1}\right)$. The catalyst showed excitingly high ORR activity and stability in RDE test in an acidic medium, which is almost comparable to that of JM Pt/C catalyst. The oxygen reduction on Fe-PANI/C-Mela catalyst followed the four-electron transfer pathway. However, the performance and durability of Fe-PANI/CMela catalyst $\mathrm{In}_{2}$-air single fuel cell are still much lower than those of JM Pt/C catalyst.

\section{Methods}

Catalysts preparation. Preparation of hybrid precursor Fe-PANI/C-Mela: In a typical approach, melamine $(2.0 \mathrm{~g}, \mathrm{AR},>99.5 \%)$, aniline $(4.0 \mathrm{~mL}, \mathrm{AR},>99.5 \%)$, and $\mathrm{FeCl}_{3} \cdot 6 \mathrm{H}_{2} \mathrm{O}(1.5 \mathrm{~g}, \mathrm{AR},>99.0 \%$ the ratio of the $\mathrm{Fe}$ is $5 \mathrm{wt} \%$ of the melamine and aniline) were first dispersed in $0.75 \mathrm{M} \mathrm{HCl}$ solution $(120 \mathrm{~mL})$ and the mixture was stirred in ice bath for 30 minutes. Afterwards, oxidant ammonium peroxydisulfate $(10.0 \mathrm{~g}, \mathrm{AR},>98.0 \%)$ was added slowly as the polymerizing catalyst. After constant stirring for 24 hours below $10^{\circ} \mathrm{C}$ for the completely polymerization of aniline, the mixture was evaporated to remove the solvent, thus the hybrid precursor was obtained. Pyrolysis: the catalysts were prepared by a twice pyrolysis process, firstly, the hybrid precursor was pyrolyzed from $700-1000^{\circ} \mathrm{C}$ in an argon atmosphere for 1.0 hour, then the sample is leached in $0.5 \mathrm{M} \mathrm{H}_{2} \mathrm{SO}_{4}$ at $80^{\circ} \mathrm{C}$ for 10 hours, followed by thoroughly washing with de-ionized water. Finally, the catalyst was obtained by pyrolyzing the leached sample in an argon atmosphere for 3.0 hours at the same temperature; we denote the catalyst as Fe-PANI/C-Mela. (when the ratio of aniline: melamine was $1: 2$ by weight, denote Fe-PANI/C-Mela-1/2).

For comparison, we prepared a series of doped catalysts with almost same procedures, such as PANI/C-Mela, C-PANI and C-Mela prepared without addition of $\mathrm{FeCl}_{3} \cdot 6 \mathrm{H}_{2} \mathrm{O}$, prepared without addition of melamine and $\mathrm{FeCl}_{3}$ and prepared by pyrolyzing from pure melamine at $900^{\circ} \mathrm{C}$, respectively. powder diffractometer (Tongda, China) operated at $40 \mathrm{kV}$ and $30 \mathrm{~mA}$, using $\mathrm{Cu}-\mathrm{K} \alpha$ radiation sources. Raman measurement was performed on a LabRAM Aramis Raman spectrometer (HJY, France) with a laser wavelength of $532 \mathrm{~nm}$. Fourier transform infrared spectroscopy (FTIR) was recorded with a Tessor 27 (Bruke, Germany). X-ray photoelectron spectroscopy (XPS) was performed on an Axis Ultra DLD X-ray photoelectron spectrometer (Kratos, England) employing a monochromated Al-Ka $\mathrm{X}$-ray source $(\mathrm{h} v=1486.6 \mathrm{eV})$. Specific surface areas were measured by BrunauerEmmett-Teller (BET) nitrogen adsorption-desorption on a TristarII 3020 (Micromeritics, USA) gas adsorption analyzer.

Catalysts evaluation. ORR activity. The ORR performances of the catalysts were evaluated on an electrochemical workstation (Ivium, Netherlands) at room temperature, using a three-electrode electrochemical cell. The work electrode was prepared with following procedures: $5 \mathrm{mg}$ catalyst were dispersed ultrasonically in $1 \mathrm{~mL}$ Nafion/ethanol (0.25 wt.\% Nafion) for 1.0 hour, then $20 \mu \mathrm{L}$ catalyst dispersion was pipetted and spread on the glassy carbon electrode ( $5 \mathrm{~mm}$ inner diameter), followed by drying under an infrared bulb. A platinum wire and $\mathrm{Ag} / \mathrm{AgCl}(3 \mathrm{M} \mathrm{NaCl})$ $\left(\mathrm{E}[\mathrm{RHE}]=\mathrm{E}[\mathrm{Ag} / \mathrm{AgCl}]+0.290 \mathrm{~V}\right.$ in $0.1 \mathrm{M} \mathrm{HClO}_{4}$ electrolyte $)$ were used as the counter and reference electrodes, respectively. ORR steady-state polarization measurements were conducted in oxygen-saturated $0.1 \mathrm{M} \mathrm{HClO}_{4}$ electrolyte with scanning rates of $10 \mathrm{mV} \mathrm{s}^{-1}$. For doped carbon catalysts, the loadings is $0.51 \mathrm{mg}$ $\mathrm{cm}^{-2}$, and for JM Hispec 4100, $\mathrm{Pt} / \mathrm{C}$ catalyst, the loadings is $51 \mu \mathrm{g} \mathrm{Pt} \mathrm{cm}{ }^{-2}$.

ORR stability. The Melamine-PANI-Fe has been investigated by continuous potential cycling in air-saturated $0.1 \mathrm{M} \mathrm{HClO}_{4}$ between 0.39 and $1.14 \mathrm{~V}$ with the scan rate at $0.10 \mathrm{~V} / \mathrm{s}$. And after some continuous cycles, the ORR steady-state polarization measurements were conducted in oxygen-saturated $0.1 \mathrm{M} \mathrm{HClO}_{4}$ electrolyte with scanning rates of $10 \mathrm{mV} \mathrm{s}^{-1}$ and rotation rate at $1600 \mathrm{rpm}$.

The fuel cell performance of the doped carbon catalyst as a cathode was tested at a single cell system. The MEAs with an active area of $5.0 \mathrm{~cm}^{2}$ were fabricated using the catalyst-sprayed membrane method reported previously by our research group ${ }^{41}$. First, the slurry of Fe-PANI/C-Mela catalyst was prepared by ultrasonically mixing of catalyst powders, isopropanol, 5 wt.\% Nafion ionomer solution (DuPont, USA) for 1 hour. Then the slurry was sprayed on the one side of a pretreated Nafion 212 membrane (DuPont, USA) to form the cathode catalyst layer; Commercial Hispec $4100 \mathrm{Pt} / \mathrm{C}$ catalyst was used as an anode, the anode catalyst ink was prepared by the same method, and sprayed on the another side of the membrane to form the anode catalyst layer. The dry Nafion content in both anode and cathode catalyst layer (CL) was 25 wt.\%. The Fe-PANI/C-Mela catalyst loadings in the cathode were $4 \mathrm{mg} \mathrm{cm}^{-2}$ and Pt loadings in the anodes were $0.1 \mathrm{mg} \mathrm{cm}^{-2}$ respectively. Single fuel cell was assembled with the as-prepared MEAs and two pieces of gas diffusion layers on the both sides. $\mathrm{H}_{2}$ and air were used as the fuel and oxidant with $30 \mathrm{psi}$ in the test process. Fuel cell polarization plots were recorded using fuel cell test stations (Arbin Instruments, USA). Pure hydrogen and air, humidified at $80^{\circ} \mathrm{C}$, were fed to the anode and cathode, respectively, at flow rates of $300 \mathrm{~cm}^{3} \mathrm{~min}^{-1}$ (hydrogen) and $800 \mathrm{~cm}^{3}$ $\mathrm{min}^{-1}$ (air) using fully humidified gases.

The gas diffusion layers (GDLs) for anode and cathode were prepared by the following procedures ${ }^{41}$. In a typical approach, first, TGP-H-060 carbon paper (Toray, Japan) was hydrophobically treated by impregnating the paper with a Teflon dispersion and calcining at $400^{\circ} \mathrm{C}$ for $30 \mathrm{~min}$; then, a slurry of carbon black and Teflon, with a composition of $85 \mathrm{wt} . \%$ carbon powder (Vulcan XC72, Cabot, USA) and 15 wt.\% polytetrafluoroethylene (PTFE) (60\%, Aldrich, USA), was sprayed onto the pretreated carbon paper, followed by calcining at $400^{\circ} \mathrm{C}$ for $30 \mathrm{~min}$ in air.

1. Su, D. S. \& Sun, G. Q. Nonprecious-metal catalysts for low-cost fuel cells. Angew. Chem. Int. Ed. 50, 11570-11572 (2011).

2. Liao, S., Holmes, K. A., Tsaprailis, H. \& Birss, V. I. High performance PtRuIr catalysts supported on carbon nanotubes for the anodic oxidation of methanol. J. Am. Chem. Soc. 128, 3504-3505 (2006).

3. Wu, G., More, K. L., Johnston, C. M. \& Zelenay, P. High-performance electrocatalysts for oxygen reduction derived from polyaniline, iron, and cobalt Science 332, 443-447 (2011).

4. Gasteiger, H. A., Kocha, S. S., Sompalli, B. \& Wagner, F. T. Activity benchmarks and requirements for $\mathrm{Pt}, \mathrm{Pt}$-alloy, and non-Pt oxygen reduction catalysts for PEMFCs. Appl. Catal., B 56, 9-35 (2005).

5. Mo, Z., Liao, S., Zheng, Y. \& Fu, Z. Preparation of nitrogen-doped carbon nanotube arrays and their catalysis towards cathodic oxygen reduction in acidic and alkaline media. Carbon 50, 2620-2627 (2012).

6. Chen, Z., Higgins, D., Yu, A., Zhang, L. \& Zhang, J. A review on non-precious metal electrocatalysts for PEM fuel cells. Energ. environ. Sci. 4, 3167-3192 (2011).

7. Debe, M. K. Electrocatalyst approaches and challenges for automotive fuel cells. Nature 486, 43-51 (2012)

8. Baker, R., Wilkinson, D. P. \& Zhang, J. Facile synthesis, spectroscopy and electrochemical activity of two substituted iron phthalocyanines as oxygen reduction catalysts in an acidic environment. Electrochim. Acta 54, 3098-3102 (2009).

9. Choi, J. Y., Hsu, R. S. \& Chen, Z. Highly Active Porous Carbon-Supported Nonprecious Metal-N Electrocatalyst for Oxygen Reduction Reaction in PEM Fuel Cells. J. Phys. Chem. C 114, 8048-8053 (2010). 
10. Liu, G., Li, X., Ganesan, P. \& Popov, B. N. Development of non-precious meta oxygen-reduction catalysts for PEM fuel cells based on $\mathrm{N}$-doped ordered porous carbon. Appl. Catal., B 93, 156-165 (2009).

11. Ishihara, A., Ohgi, Y., Matsuzawa, K., Mitsushima, S. \& Ota, K.-i. Progress in nonprecious metal oxide-based cathode for polymer electrolyte fuel cells. Electrochim. Acta 55, 8005-8012 (2010)

12. Gong, K., Du, F., Xia, Z., Durstock, M. \& Dai, L. Nitrogen-doped carbon nanotube arrays with high electrocatalytic activity for oxygen reduction. Science $\mathbf{3 2 3}$, 760-764 (2009).

13. Wang, S. et al. BCN graphene as efficient metal-free electrocatalyst for the oxygen reduction reaction. Angew. Chem. Int. Ed. 51, 4209-4212 (2012).

14. Wu, Z. S. et al. 3D nitrogen-doped graphene aerogel-supported $\mathrm{Fe} 3 \mathrm{O} 4$ nanoparticles as efficient eletrocatalysts for the oxygen reduction reaction. J. Am. Chem. Soc. 134, 9082-9085 (2012).

15. Lv, R. et al. Nitrogen-doped graphene: beyond single substitution and enhanced molecular sensing. Sci. Rep. 2, 586-593 (2012).

16. Wu, G. et al. Synthesis-structure-performance correlation for polyaniline-Me-C non-precious metal cathode catalysts for oxygen reduction in fuel cells. J. Mater. Chem. 21, 11392-11405 (2011).

17. Proietti, E. et al. Iron-based cathode catalyst with enhanced power density in polymer electrolyte membrane fuel cells. Nat. Commun. 2, 416-424 (2011).

18. Yu, D., Nagelli, E., Du, F. \& Dai, L. Metal-free carbon nanomaterials become more active than metal catalysts and last longer. J. Phys. Chem. Lett 1, 2165-2173 (2010).

19. Lefevre, M., Proietti, E., Jaouen, F. \& Dodelet, J. P. Iron-based catalysts with improved oxygen reduction activity in polymer electrolyte fuel cells. Science 324, 71-74 (2009).

20. Liang, Y. et al. Co3O4 nanocrystals on graphene as a synergistic catalyst for oxygen reduction reaction. Nat Mater 10, 780-786 (2011).

21. Yang, S., Feng, X., Wang, X. \& Müllen, K. Graphene-based carbon nitride nanosheets as efficient metal-free electrocatalysts for oxygen reduction reactions. Angew. Chem. Int. Ed. 50, 5339-5343 (2011).

22. Zhang, H. B. et al. A facile approach to the synthesis of graphene nanosheets under ultra-low exfoliation temperature. J. Nanosci. Nanotechno. 11, 10868-10870 (2011).

23. Bezrodna, T. et al. Pyridine- $\mathrm{TiO}_{2}$ surface interaction as a probe for surface active centers analysis. Appl. Surf. Sci. 214, 222-231 (2003).

24. Park, S., Dikin, D. A., Nguyen, S. T. \& Ruoff, R. S. Graphene oxide sheets chemically cross-Linked by polyallylamine. J. Phys. Chem. C 113, 15801-15804 (2009).

25. Li, X. et al. Simultaneous nitrogen doping and reduction of graphene oxide. J. Am. Chem. Soc. 131, 15939-15944 (2009).

26. Souza, F. G. et al. New in situ blends of polyaniline and cardanol bio-resins. Macromol. Mater. Eeg. 293, 675-683 (2008).

27. Yun, J. M. et al. DNA origami nanopatterning on chemically modified graphene. Angew. Chem. Int. Ed. 51, 912-915 (2012).

28. Choudhury, D., Das, B., Sarma, D. D. \& Rao, C. N. R. XPS evidence for molecular charge-transfer doping of graphene. Chem. Phys. Lett. 497, 66-69 (2010).

29. Li, Z., Chen, H., Bao, H. \& Gao, M. One-Pot Reaction to Synthesize Water-Soluble Magnetite Nanocrystals. Chem. Mater. 16, 1391-1393 (2004).

30. Mills, P. \& Sullivan, J. L. A study of the core level electrons in iron and its three oxides by means of X-ray photoelectron spectroscopy. J. Phys. D: Appl. Phys. 16, 723-732 (1983).

31. Siriwardane, R. V. \& Cook, J. M. Interactions of $\mathrm{SO}_{2}$ with sodium deposited on silica. J. Colloid Interface Sci. 108, 414-422 (1985).
32. Marcus, P. \& Grimal, J. M. The anodic dissolution and passivation of NiCrFe alloys studied by ESCA. Corros. Sci. 33, 805-814 (1992).

33. Lefèvre, M. \& Dodelet, J. P. Fe-based catalysts for the reduction of oxygen in polymer electrolyte membrane fuel cell conditions: determination of the amount of peroxide released during electroreduction and its influence on the stability of the catalysts. Electrochim. Acta 48, 2749-2760 (2003).

34. Marković, N. M., Gasteiger, H. A., Grgur, B. N. \& Ross, P. N. Oxygen reduction reaction on Pt(111): effects of bromide. J. Electroanal. Chem. 467, 157-163 (1999).

35. Xu, Z. \& Gao, C. Graphene chiral liquid crystals and macroscopic assembled fibres. Nat. Commun. 2, 571-579 (2011).

36. Bezerra, C. W. B. et al. A review of heat-treatment effects on activity and stability of PEM fuel cell catalysts for oxygen reduction reaction. J. Power Sources 173, 891-908 (2007).

37. Liu, R., Wu, D., Feng, X. \& Müllen, K. Nitrogen-Doped Ordered Mesoporous Graphitic Arrays with High Electrocatalytic Activity for Oxygen Reduction. Angew. Chem. Int. Ed. 49, 2565-2569 (2010).

38. Kim, H., Lee, K., Woo, S. I. \& Jung, Y. On the mechanism of enhanced oxygen reduction reaction in nitrogen-doped graphene nanoribbons. PCCP 13, 17505-17510 (2011).

39. Oh, H. S. \& Kim, H. The role of transition metals in non-precious nitrogenmodified carbon-based electrocatalysts for oxygen reduction reaction. J. Power Sources 212, 220-225 (2012).

40. Biddinger, E. J., Deak, D. \& Ozkan, U. S. Nitrogen-containing carbon nanostructures as oxygen-reduction catalysts. Top. Catal. 52, 1566-1574 (2009).

41. Su, H. N., Liao, S. J., Shu, T. \& Gao, H. L. Performance of an ultra-low platinum loading membrane electrode assembly prepared by a novel catalyst-sprayed membrane technique. J. Power Sources 195, 756-761 (2010).

\section{Acknowledgments}

This work was supported by the National Scientific Foundation of China (Project Numbers $21076089,20876062,26073040)$ and Doctoral Fund of Ministry of Education of China (20110172110012)

\section{Author contributions}

H.P., Z.M., S.L., H.L., L.Y. and B.Z. synthesized the catalysts, prepared the fuel cell test materials and/or conducted fuel cell tests and processed the data. H.P., L.Y., F.L., H.S. and Y.Z. performed physical characterizations (XPS, HRTEM, XRD, Roman, FTIR and BET). H.P., Z.M., S.L., H.L. and L.Y. wrote and edited the manuscript. All authors contributed to discussions about the results and the manuscript. S. L. supervised and directed the project.

\section{Additional information}

Supplementary information accompanies this paper at http://www.nature.com/ scientificreports

Competing financial interests: The authors declare no competing financial interests.

License: This work is licensed under a Creative Commons Attribution-NonCommercial-NoDerivs 3.0 Unported License. To view a copy of this license, visit http://creativecommons.org/licenses/by-nc-nd/3.0/

How to cite this article: Peng, H.L. et al. High Performance Fe- and N-Doped Carbon Catalyst with Graphene Structure for Oxygen Reduction. Sci. Rep. 3, 1765; DOI:10.1038/ srep01765 (2013) 